\title{
Information Infrastructures and Public Goods: Analytical and Practical Implications for SDI
}

\author{
Margunn Aanestad \\ Department of Informatics, University of Oslo, Norway. E-mail: margunn@ifi.uio.no \\ Eric Monteiro \\ Department of Computing and Information Sciences, NTNU, Norway. \\ E-mail: ericm@idi.uio.no \\ Petter Nielsen \\ Telenor Research and Innovation, Telenor ASA, Fornebu, Norway. \\ E-mail: petter.nielsen@telenor.com
}

\begin{abstract}
Spatial Data Infrastructures (SDIs) are envisioned to increase efficiency, transparency and equity, but realising this potential has proven problematic. We argue that insights from studies of large-scale, integrated but distributed information systems, dubbed "information infrastructures," are applicable. This perspective may help address an important dimension of SDIs: their character of being public goods rather than private assets. We identify and illustrate four key aspects of information infrastructures that underpin such a public good's focus. First, we advocate the necessity of deploying a socio-technical rather than a limited technical perspective. We further argue that the notion of installed base is central, that it is important to be aware of the "politics of representations" and to accept the unavoidable "messiness" of reality. We illustrate these concepts through examples from health care in developing countries, an area particularly concerned with the potential to increase equity. (C) 2007 Wiley Periodicals, Inc.
\end{abstract}

Keywords: information infrastructures; spatial data infrastructures; SDI; geographical information systems; GIS; public goods; health care socio-technical; installed base

\section{INTRODUCTION}

Spatial data technologies make it possible to have available rich sources of spatial datamaps, technical installations (sanitation, drainage, sewers, roads, cables), human indicators (health service coverage, socio-economical demographic data, housing, overview of social institutions such as schools, hospitals) or natural resources (water, environmental data, vegetation). Thus, spatial data technologies are embraced as promising tools for policy and decision making, planning or ongoing maintenance. The possibilities of using spatial data technologies to generate easily understandable, graphical overviews of relevant aspects of a context comes with the potential for promoting increased transparency, equity, and

Sundeep Sahay is the accepting guest editor for this article. 
equal access to resources in our societies (Walsham \& Sahay, 1999). At the same time, realizing these potentials requires more than implementing a geographical information system (GIS). Obviously, it requires GIS systems but also multiple sources of spatial data (both gathering technologies and databases), standards and systems (for accessing, processing, and integrating these data sources), as well as a host of applications to generate services for various users and usage areas. These collections of multiple heterogeneous resources are often conceptualized as spatial data infrastructures (SDI) offering a shared resource for geographical information delivery and exchange for different applications and communities that appropriate them for their respective purposes.

This article takes as a point of departure that establishing such SDIs will involve a range of challenges of technical, social, and political nature, which will be both similar to and also different from those of relatively independent geographical information systems. Studies of the challenges of GIS implementation have often voiced critique of the limited focus of GIS initiatives. For example, the primary challenges have often been seen as technical, which has led to an emphasis on technical excellence and ingenuity of GISs that comes at the expense of for example practical work outside the lab (Groot, 1997) and use relevance (Sahay \& Walsham, 1997). Further, during the process of GIS implementation project teams have often neglected end-users' and other stakeholders' involvement (Puri, 2003) or there is a failure to ensure adequate managerial backing and political support (de Man, 2004; Georgiadou, Puri, \& Sahay, 2005b; Giff \& Coleman, 2002; Groot, 1997; Ndengu, 2001). This neglect has had detrimental effects on the required institutional, organizational, and human resource development, and recent research has emphasized the importance of, for example, the need for sustainable funding arrangements and business models (Giff \& Coleman), as well as the need to view human and technical components as both allies and opponents in implementation processes (see de Man, 2004; Georgiadou et al., 2005b; Rajabifard, 2002). These insights relating to the establishment of individual GIS will also hold in the context of SDIs. However, SDIs are expected to operate on a different scale than individual GIS both in terms of reach and range, and this entails challenges of a different character as well. These challenges are the topic of the remainder of this section.

The present special issue suggests that researchers should explore the potential of crosslearning between the geospatial community and information systems field, in particular information infrastructure theory. The notion of "infrastructure" has served as a metaphor in the visions of national and global information superhighways, as is also evident in the concept of SDI and in the naming of several large initiatives within the spatial data research community. For instance, the European Commission aims at developing the "Infrastructure for Spatial Information in Europe," the Indian government proposes to build a "National Spatial Data Infrastructure" (Georgiadou, 2003), and there are visions for an "Asian-Pacific Spatial Data Infrastructure" (APSDI; Rajabifard, 2002). A fundamental premise of information infrastructure theory is that information systems are understood as integrated parts of large-scale networks rather than independent and standalone systems. Information systems researchers have suggested that our current conceptual understanding is not adequate when we study and interact with such large and complex assemblages of systems and that common strategies for developing information systems fail to take into account the nature of these large-scale networks. Of particular importance, in this respect, is their (a) heterogeneous (socio-technical) nature, (b) their dependence on standards, (c) the dispersed and incremental fashion in which they evolve, and (d) the role of the installed base.

${ }^{1}$ INSPIRE, see http://inspire.jrc.it 
Consequently, researchers argue that these large collections of networked systems should rather be conceptualized as information infrastructures (see Ciborra et al., 2000; Hanseth \& Lyytinen, 2004; Hanseth \& Monteiro, 1997).

Research drawing on information infrastructure theory has often aimed at offering design implications. Small-scale, bottom-up, incremental, and evolutionary approaches are seen as appropriate for managing the particular complexity of infrastructures. Also, strategies that are sensitive to the economic mechanisms in networks are advocated, such as advice on how to act in order to overcome startup problems (Hanseth \& Aanestad, 2003) or lock-in situations due to the decisive role of the installed base (Hanseth \& Lyytinen, 2004; Monteiro, 1998). There is, however, a significant space for deliberate and improvisational action in relation to shaping the growth, kind, and direction of emerging information infrastructures (see e.g., Nielsen, 2006). Our aim with this article is not to reiterate these insights, whose implications for SDI are already well described by several researchers (e.g., Georgiadou, Puri, \& Sahay, 2005c). Instead, we have chosen to present and discuss a slightly different selection of concepts geared more towards the shared nature of SDIs, the reasons for which are discussed below.

To highlight and supplement a perspective on information infrastructure as shared and open, we employ elements of public goods theory. Public or collective goods are goods that all members within the interest group will benefit from, regardless of whether they contribute in creating or sustaining it such as clean air or roads. Of particular relevance to our perspective on SDI is the way public goods concepts underscore the complex links and dependencies between the private and public sector, for example in the ownership of maps. A not uncommon situation (particularly in developing countries) is that the defense establishment has the control over spatial data for security reasons. GIS systems may be implemented, but the limited access to maps coupled with a bureaucratic public sector (that is often inherited from the colonial past) may severely impede the growth of SDIs for the more general public (Georgiadou et al., 2005b; Ndengu, 2001; Rajabifard, 2002). Because of these factors, establishing an SDI will entail specific types of challenges: An SDI may have benefits for all actors, but actually establishing it will entail costs and investments that are not equally shared among them.

The remainder of this article discusses a set of concepts that we believe will be valuable for opening up the perspectives for building SDIs that contribute to socio-economic development. The first section elaborates the potential role of SDIs as a shared resource for improving health care and socio-economic development by drawing on relevant notions borrowed from public goods theory. The remaining sections, except section 7, identify, explain, and illustrate key notions from information infrastructure theory and their relevance for SDI in health care.

\section{SDI, DEVELOPMENT, AND PUBLIC GOODS}

\subsection{SDIs Potential Role in Improvement of Health Care}

Providing improved access to the health care for its people is a highly prioritized aim of any (developing) country. There is also growing acceptance for the potential role of information systems support in achieving this aim. Furthermore, as a consequence of recent critiques of traditional models of development (Sen, 2000), improved health care is viewed not only as an indicator of development but also as a driver of development with rich spillover effects. 
In the words of the 1993 World Development Report, "Because good health increases the economic productivity of individuals and the economic growth rate of countries, investing in health is one means of accelerating development. More important, good health is a goal in itself" (World Bank, 1993). Strengthening health care provision through improving the information systems in developing countries is accordingly intrinsically linked with promoting development in general.

There is a strong political concern for equal, fair distribution of and access to health care services in developing countries. This is manifest on a number of levels. The World Health Organization (WHO, 1978) already in the late 1970s formulated their "health for all" policy, advocating a minimum level of health services to all citizens. Needless to say, materializing these visions has proven notoriously difficult. Yet, these visions still function as a productive platform when launching new efforts. Establishing SDIs within health care is attractive for developing countries exactly for their potential to deliver (or at least get closer to delivering) the promises embedded in the WHO's visions. SDIs may be used to generate useful and policy relevant overviews of a number of issues related to effective health care delivery by presenting health indicators in a readable form (e.g., immunization coverage in various geographical regions or the relative density of outbreaks of communicable diseases, such as malaria, tuberculosis, HIV/AIDS, dengue fever). Health care planners need multifaceted information as many socio-economical demographic indicators, relating to (i.e., educational level or water supply), have strong relevance to health status (Clarke, McLafferty, \& Tempalski, 1996).

To illustrate the potential of utilizing spatial data technologies for socio-economic development, we describe the attempts to eradicate river blindness in West Africa. The following case demonstrates a number of key issues we pursue in more depth in subsequent sections.

River blindness (onchocersiasis) has been endemic around river basins throughout tropical Africa, but despite its debilitating effects (related to both blindness and skin problems), the disease initially received scant attention from the world, as it is nonfatal, predominantly rural, and affects the poorest. The Onchocerciasis Control Programme was launched in 1974 and covered seven West African countries.

When it was terminated in December 2002, it had achieved remarkable success with interrupting transmission in most parts of the original program area, so that river blindness was no longer a public health problem (Dadzie, Neira, \& Hopkins, 2003). It is estimated that around 600,000 cases of blindness had been prevented and that around 25 million hectares of fertile riverside land, previously deserted for fear of the disease, could again be inhabited (Etya'alé 2002). Aerial spraying of the infested rivers was conducted when the conditions were favourable for the vector (the blackfly larvae) to develop. In addition, mass distribution of medication to the infected population proved successful (Hougard et al., 2001).

In order to manage this enormous undertaking, a cost effective mapping and assessment method was developed, the Rapid Epidemiological Mapping of Onchocerciasis (REMO). Data on prevalence were collected and incorporated into a GIS (Etya'alé, 2002). The GIS was used both as a database and as a graphical tool, and it helped to identify communities requiring mass treatment and prioritize interventions. It also helped the managers discover new foci for the disease (Bergquist, 2001).

The visual presentation of data provided crucial, for instance when the adequacy of sample coverage should be assessed during the survey phase. Initially a particular district was assumed well covered. However, when the location of the sample point villages were displayed on an electronic map via the GIS, it was found that all villages were located within 
a $10 \mathrm{~km}$ circle, and large areas of the district were not covered (WHO, 1998). Another useful function of the GIS was the possibility to overlay multiple maps. Serious adverse effects to the medication were observed in places where river blindness was co-endemic with another disease called loa loa. Remote sensing data on vegetation indices that suggested breeding sites for the loa loa vector were used to generate maps of overlapping endemicity, and special measures were then undertaken in these risk areas (Dadzie et al., 2003).

This example demonstrates the crucial contribution spatial data technologies can offer to health care provision and thus more broadly to socio-economic development. We will return to this example in the subsequent sections, but first we will discuss our selection of theoretical concepts.

\subsection{Shared Information Infrastructures}

The literature on information infrastructures have provided useful insights into how they develop and how to engage in their building. We do not offer a general introduction to the theory, but refer to other works (e.g, Ciborra et al., 2000; Hanseth \& Lyytinen, 2004; Hanseth \& Monteiro, 1997). In this article, we have chosen to focus specifically on the political aspects that are associated with the shared nature of such information infrastructures. We argue that an adequate understanding of these aspects will be crucial if SDIs that support development and equity shall become realized. To address these aspects, we draw upon relevant contributions from the field of Science and Technology Studies (STS), as well as from urban planning. These studies do, in particular, demonstrate the political dimensions of representations, systems, and infrastructures. They also critically reexamine the takenfor-granted visions of all-encompassing, universal infrastructures. Further, they illustrate that it is contested how the society shall organize issues of infrastructures, for example, what should be a public responsibility.

A well-known study from urban planning examines what happened when hierarchic monopolies were replaced by privatization of water and waste supply, gas, electricity, and telecommunications networks in Great Britain (Guy, Graham, \& Simon, 1997). During the last decades, the challenges of administrating technological infrastructures have been increasing, and control regimes have moved from being centralized and bureaucratic towards deploying various kinds of market mechanisms. These changes have reconfigured how the urban technical infrastructures are provided and managed, and the main message of the authors is that these changes lead to increased socio-spatial unevenness. Their study focuses on the "splintering" of these previously universal service infrastructures (i.e., the segmentation of customer groups and the resulting socio-spatial polarisation). A prevalent strategy is "cherry picking," where the providers target the most affluent customers and market segments. On the other side of the spectrum are inner city inhabitants who increasingly have to use prepayment of, for example, gas and electricity, a practice that is effectively hiding exclusion to what used to be public services. The ensuing "splintering" of the provision of basic infrastructural services demonstrates how the configurations of these technological infrastructures are of vital importance to the makeup of our societies and the controversies that surround attempts to reorganize what used to be homogeneous and universal service infrastructures.

We want to focus on the central nature of information infrastructures to society and on the ensuing contests and politics around establishing and managing them. In the next section, we discuss a concept that we believe is a resource for analyzing and discussing this political dimension of infrastructure building - the notion of public goods. 


\subsection{Public Goods}

The term public goods has a long ancestry within political economy and in 1776 Adam Smith recognized the limits of the market as he noted the existence of certain products that:

Though they may be in the highest degree advantageous to a great society are, however, of such a nature that the profits could never repay the expenses to any individual or small number of individuals, and which it therefore cannot be expected that any individual or small number of individuals should erect (1994, p. 779, cited in Kaul, Grunberg, \& Stern, 1999).

The examples he mentioned include structures for maintaining the money supply, enforcing property rights, promoting competitive markets, and providing national defence and administering justice. The term has enjoyed an increasing popularity beyond the economic community, and has recently been taken up by major actors in global development policy, like the UN agencies (Kaul, Conceicao, Le Goulven, Mendoza, 2003; Kaul et al., 1999). The definition of public goods we use here is:

- goods that benefit many or all; they are non-excludable

- consumption by one person doesn't prevent consumption by another; they are nonrival in consumption

For example, traffic signs or traffic lights are for the good of all (who travel) and they will not wear out even if large numbers of people are looking at it. ${ }^{2}$ Public goods are often equated with state-provided goods but this is not always so. A private good is, on the contrary, excludable and rival in consumption, and most of the goods that we purchase and consume belong to this category. Between the public and the private goods, there also exist some middle varieties, often called common pool goods (nonexcludable but rival) and club goods (nonrival but excludable). While recognizing that these notions can be further discussed and elaborated (e.g., how the criteria of rivalry and excludability may be relative and not absolute), our emphasis is on this elaboration: pointing to the potential of these notions to inform design and development of SDIs.

Historical or comparative studies of how societies are organized reveal huge varieties with regard to the distinction between private and public goods. The goods that fall into the categories of club goods and common goods have been organized differently. In medieval Europe, hospitals were, for example, run and funded by churches and charities, and the provision of health care was not considered a state or societal responsibility as it is today (Desai, 2003). We mention this as a reminder that we create our societies, they are not "naturally given." Similar discussions on the makeup of SDIs are evident. For instance, access to the new spatial data infrastructures has been a topic of discussion, with significant variations in national access policies (Craglia \& Masser, 2001). The ownership of maps-a particularly good example of how the new distinction between public and private goods that needs to be redrawn - is not simple. While the cartographic data have often been gathered by official or semi-official entities financed by the taxpayer's money, commercial entities (in several countries) are set up to generate value-added services based on these maps. This has spurred contest as to whether the basemaps should be freely or, at least, publicly

\footnotetext{
${ }^{2}$ Such goods may be, at the same time, highly political. For example, traffic light intervals can favor pedestrians over cars or public over private transportation, and thus influence the means of transportation used and traffic patterns in general.
} 
available; should maps be regarded as public goods? In issues such as this, what should be public and what should be private is not given by any natural, economic, or social necessity; on the contrary it is up for "design."

\subsection{SDI for Health as Public Goods}

Eradication of communicable (or infectious) diseases is an example of how the benefits of action may extend beyond the primary beneficiary. The existence of communicable diseases is a public bad, and its eradication can be seen as a public good. Preventing one person from getting a communicable disease doesn't improve life for this person only, but also reduces the risk of infection for others and contributes to the overall socio-economic development. In our current world, rumours of outbreaks of infectious diseases will also more widely affect trade and tourism (Zacker, 1999). The monitoring and control of infectious diseases thus has positive externalities; if diseases are controlled and eradicated, everybody will benefit, not just those directly affected. Deciding on the actual distribution of burdens and benefits is not straightforward, as it touches upon the dilemmas of collective action. As has been long recognized by game theorists, the actions that are rational for the individual are not necessarily rational for the collective, and the other way around.

The use of SDIs in the eradication of river blindness illustrates very well the need to resolve such a "collective action" dilemma and manage to engage several partners. The challenges that river blindness posed were too complex and expensive to handle by individual entities and nation states alone. The worm's long lifespan (up to 14 years in infected humans), the prevalence of infected population (river blindness being endemic with up to $40 \%$ of the adult population infected in some areas), and the long flight range of the vector (the blackfly) implied significant technical difficulties to attempts at controlling its spread. Addressing these issues on a national scale only was not feasible, as the blackfly is able to fly up to several hundred kilometres with the aid of seasonal winds. Moreover, there were significant amounts of population migrations (both forced and voluntary) that would contribute to the spread of the disease. River blindness was a trans-national public bad, and, consequently, required trans-national or even global collective action in order for it to be resolved. When the Onchocersiasis Control Programme (OCP) was launched in 1974, it comprised many previously distant groups. The OCP was a unique publicprivate partnership, bringing together governments of the afflicted states, pharmaceutical companies, other nation's donor agencies, the WHO and other UN agencies, the World Bank, and NGOs. Problems and readjustments were necessary as the project went along. There were complications and reinfections due to the blackfly's flight range being even longer than expected, from residual loci, and due to the migration of the population. The achievements were hard won and required continuous work. The possibilities for blackfly breeding associated with the building of new dams were carefully surveyed and, after the end of the OCP in 2002, the residual activities of surveillance and control are left to the participating countries. ${ }^{3}$

\subsection{The Politics of Technology}

We end this review of relevant literature with another empirical example from the use of information technology used to improve health care for development. The Health Information

\footnotetext{
${ }^{3}$ See e.g., www.hisp.org, www.hisp.info or Braa et al., 2004.
} 
Systems Programme ${ }^{4}$ is a loosely connected global network for sharing and development of open source software for the health sector in developing countries. The initial phases of HISP took place in South Africa immediately after the takeover of the African National Congress (ANC). Amending the devastating effects of apartheid on the health care sector had top priority. Health services and their institutions were fragmented across "white," "coloured," and "black," and, as a result, the services were distributed dramatically unevenly during apartheid. As Braa and Hedberg (2002) write:

The politics of apartheid—segregation, centralism, and exclusion of "black" South Africans-have all been deeply inscribed into all the bits and pieces of the information systems in which standards for data collection are basic elements.(p. 113).

HISP was initiated in Cape Town and from the outset was deeply implicated in the political controversies surrounding the ANC's changes. Cape Town, where top-notch hospitals (e.g., hosting the world's first successful heart transplantation) and shanty towns were but a few miles apart, provided a vivid illustration of the challenge of redistributing material and symbolic resources. HISP was committed to boosting the capacity to generate health indicators (vaccination coverage, communicable diseases, resource figures on the number of qualified health workers) as a vehicle for achieving more equity. The core idea of HISP has always been to recognise the politically charged nature of these "numbers," the health indicators. Through lobbying, teaching, and local capacity building, HISP aimed at making explicit, thus politically "real," the extent of the inequalities (Braa \& Hedberg, 2002). The use of graphical representations and maps was recognized early on to function very effectively in conveying the message of inequity: Presenting relevant health indicators together with their geographical distribution on maps made the inequalities (literally!) graphically clear.

Our aim with this article is to emphasise the potential for SDI initiatives to contribute to a world with more equal distribution of resources. This implies development of well-working SDIs with a strong "public goods" character. We have selected a few concepts from research on other information infrastructures that we believe will be of crucial relevance if this goal shall be achieved. They are selected because they may all assist our understanding and handling of the challenges of openness and sharedness of information infrastructures. We start by discussing the importance of taking into account the socio-technical nature of information infrastructures as well as the significance of their installed base. Information infrastructures are not simply developed as technical components, but they also involve a range of people that develop, implement, and are involved in their day-to-day operation and use, with aims, values, and interests that may differ significantly from each other. While the technically interconnected nature of information infrastructures requires coordination, which may rule out some of this heterogeneity, it is crucial to acknowledge that information infrastructures are persistently "messy." The development and coordination processes are framed by the structures between the various actors and are also influenced by the values embedded in the technology. This is the reason why we discuss the "politics of representations." We argue that these concepts fit well with the public goods perspective on SDIs: that they may shed light on how certain actors control certain central parts of the information infrastructure and how their choices are essential for its development and growth.

\footnotetext{
${ }^{4}$ This case description is based on Lewis, 2005.
} 


\section{SOCIO-TECHNICAL, NOT JUST TECHNICAL}

An information infrastructure comprises materially heterogeneous elements. Utilization of technical elements depends on the presence of adequate skills, maintenance routines, and the incorporation of the technology into meaningful activities. Work routines and organizational roles are intimately intertwined with the actual information and communication technologies in use. This perspective does not separate the "technical" from the "social," but recognizes that "the development, introduction, and use of an information infrastructure is an involved socio-technical process of negotiations" (Monteiro, 2000, p. 71). Designing information infrastructures is thus not simply a technical venture, but equally (and in some instances more importantly), a project of enrolling other actors through aligning their interests and practices.

This implies that if successful SDIs are to be implemented, technology is just one component. If we examine the work required to establish the surveillance structure for river blindness, the Rapid Epidemiological Mapping of Onchocersiasis (REMO), we will clearly see the mixture of social, technical, and even political matters. Glancing through the first few pages of one of the WHO's training manuals (WHO, 1998) reveals that the program staff in a new location are given a lot of different tasks. They should start with acquiring paper maps of the appropriate scale, define intervention zones, and document the rationale for this zone definition. A complicating factor here is that the administrative boundaries do not necessarily match with the relevant "ecological zones" that are of interest to vector control. Further, sample villages - both high risk and secondary sample sitesmust be selected. The guidelines also contain instructions on how to adjust the strategy if the selected villages cannot be found or are inaccessible during the survey times. Before a survey, teams of data collectors must also be trained, equipped, and dispatched. During fieldwork the coordinates from maps and a GPS system should be noted for each village, using paper survey forms as well as a logbook, along with the epidemiological information to be collected. After the survey, data must be entered into the computer (e.g., with the aid of general epidemiological software, such as EPI INFO) and a DBASE file must be generated and imported into the GIS. With the aid of the electronic basemap provided by the HealthMap, the zoning was digitized and the sample coverage (i.e., the villages visited) was reviewed for decision making adequacy

All of this had to occur before the initial analysis and planning of the programs' interventions. The next steps, which involved the administration of aerial spraying and creating a sustainable structure for distribution of medication, necessitated a prolonged and varied effort. Fundamental to the program was the belief that empowerment of the local community was critical to sustainability. The community had to make their own decisions around distribution of medication, including the selection of who would be responsible for distribution locally, how they would be paid, and the timing and method of distribution. In addition, the program had to adjust its operation in order to handle migration (both voluntary and forced) and social transience. It was critical to maintain continued operation during civil unrests, wars, and other crises. Program managers had to negotiate with the warring factions and promote health as a non-political issue, as well as conducting surveys during periods of tranquillity. For example, in Sudan, two separate but well-coordinated teams have operated on both sides of the battle line of the civil war (Dadzie et al., 2003). Creating a successful usage of the GIS comprised more than technical design decisions; it also required that these technical, organizational, and social issues were resolved. 
The venture of developing information infrastructures is not simply technical, but also a project of political negotiations to enroll other actors. Sustainable SDIs thus require sustainable social institutions in addition to technical networks and implementations. On one hand, local initiatives are precious and need to be nurtured and, on the other hand, some sort of general coordination (or standardization) is required to make things work on the more overall scale.

\section{INSTALLED BASE}

The installed base of an information infrastructure (i.e., the existing technical and nontechnical components, including technology, standards, organizational structures, practices, behavioural patterns, and social preferences of the users; Grindley, 1995), is decisive for the trajectory of further developments and change. This nature of information infrastructures implies that they are never built from scratch, but rather they are building on, extending, and enhancing existing structures. Thus, information infrastructures are evolving and will inherit both the weaknesses and the strengths of what already exists. Since information infrastructures are open and interconnected systems, both technically and socially, design and change will not simply proceed as planned, controlled, and self-contained processes. It will necessarily involve a range of human actors, components, and elements with different origins and being under multiple and different regimes of control. The different components and subnetworks of the information infrastructure have their own trajectory, nurtured by a variety of human actors with their interests, agendas, preferences, and limited as well as fluctuating control.

The nature of the installed base has strong implications on how information infrastructures can be constructed and designed. In this context, control oriented approaches are not suited, because no designer has the privilege of control or freedom from the installed base. To believe in and strive for full control and top-down approaches to design is thus overly ambitious from an information infrastructure perspective. On the contrary, small scale and bottom-up initiatives firmly based on the existing installed base may, over time, result in valuable changes (Ciborra, 2000). One example reported by Hanseth and Aanestad (2003) describes how a few dedicated champions countered scepticism, lack of funds, and regulatory constraints and managed to "bootstrap" a process where a useful telemedicine application became introduced into the health care sector. This was done by augmenting the existing health care provision system with an additional technology, rather than starting from scratch or trying to change any existing practices. In a different study of GIS in India, Sahay and Walsham (1997) emphasize the role of the installed base of Indian bureaucracy, powerfully shaped by various aspects of Indian culture, institutions, and a legacy from the administrative structures of the British colonial power. The particular form and scope of a managerial agency in this setting significantly shaped the process of introducing GIS technology, hampering successful introduction and usage. These two examples, moreover, illustrates how the installed base is (or can be) both a resource for expansion and growth and a constraining factor.

\subsection{The HISP GIS Module}

We would like to illustrate the impact of the installed base with another example from the HISP project previously mentioned. ${ }^{1}$ From its inception in South Africa in 1994, the 
software has been spread to several other countries. When the HISP activities were moved into a new country setting, often the HISP team members had to act as "partisans:" first in order to get the project accepted and then to sustain it in the face of various challenges and competition. One of the tactics that proved successful in this navigation was to develop a GIS module linked to the HISP software. It offered attractive possibilities for decision making in health care, as it could demonstrate aspects of health infrastructure, health indicators, and performance indicators visually. Here, we describe the impact of the installed base on one GIS module that was developed for the HISP project. The initial prototype was developed and tested in India before it was exported to Mozambique.

During the development phase in India, the usual hassle of obtaining adequate maps was the first challenge that was encountered. Indian maps are classified documents for security reasons. When appropriate maps had been purchased, the work of "cleaning" the maps started. Villages had to be linked to their respective administrative units, some villages had been renamed and some new villages had been created after the almost 10-year-old maps had been drawn. But a more significant problem, and far less reported in most of the GIS literature, was the work required in order to link the GIS application to the base data. The HISP software offers functionality for collecting and storing routine data from health facilities. This is not a database that is created for GIS use, but in which GIS is an add-on. A link between the spatial and nonspatial component that would allow user queries was created utilizing a data mart.

Further development took place when the GIS application was customized to the Mozambican context. Language translation was a central issue, as was redesign of the functionality. For example, the query feature had to be changed in order to allow analysis at other organizational levels. In the previous version developed in India, the district had been the focal point for GIS use, while, due to a lower level of computerisation in Mozambique, the provinces and the national level were targeted. However, in Mozambique most of the work efforts around this GIS module went into creating the nonspatial part of the system. This is how the installed base showed its significance. A necessary first step was to work with the nonspatial data (routine health care administrative data) before the GIS application could offer any benefits. Previously, only four out of ten routine reports had been digitized. Also, the rest of the data had to be made available before the GIS application could generate any value. Data entry screens that were identical to the old system's screens were developed to minimize resistance towards changing system, and bridges and gateways from the HISP to other central systems were created so that it could be used similarly to the old. This work, which was "only" a prerequisite before GIS could be useful, constituted a larger job than developing the GIS module itself.

This example demonstrates that the installed base of an SDI does not only concern the technical infrastructure, but also the existing social relations and institutions. As the installed base is significantly shaping development, development should take these into account. On one hand, design and implementation cannot escape the inertia of the installed base, such as legacy systems and old practices. Limitations and constraints such as these must be dealt with, negotiated, and, only over time, replaced with the new. On the other hand, we also want to emphasise that the installed base can be utilized as an enabler and a starting point. Strategically, the installed base should be built on and augmented giving new value to new users and uses. 


\section{POLITICS OF REPRESENTATION}

Information infrastructures as large technology systems (Hughes, 1979; Hughes, 1987) cannot satisfactorily be treated in isolation from organizational, economic, and political matters. They do not only have to be related to this wider context to work and grow, but they are also a product of it. Information infrastructure is composed of components developed independently by different actors with different aims, interests, and agendas, symbolizing multiple and contradictory political strategies (Barry, 2001). Linking the various components together with standards, interfaces and gateways will be necessary to create coherence by reducing heterogeneity. Such structuring and coordinating will on one hand encourage and enable, but on the other equally discourage and lock out. Through her work, Star has demonstrated the constructed and political nature of representations (e.g., Bowker \& Star, 1999; Star, 1999). "Political" in this context simply means privileging certain actors on behalf of others. The political nature of information infrastructure is not limited to its construction and development, but further permeates its usage. Representations are made ("constructed") through an effort to be real. To construct, say, a representation (i.e., a number) of the population of a country (see Porter, 1995) requires a concerted, collective effort of a range of activities. Issues such as classification (should illegal residents be counted?), the practices of counting (should one rely on probabilistic sampling or on visiting people's homes - but, then, what about the homeless?) and institutionalized competence (probability theory, demographic profiles) need to be resolved.

Standards are central parts of information infrastructures. But the shape of standards is not morally innocent or politically neutral, and interests can be inscribed even in the technical details of standards (Berg \& Timmermans, 2000; Bowker \& Star, 1999; Hanseth, Monteiro, \& Hatling, 1996). For the illustration with a country's population as indicated above, the politics amount to issues like privileging those with permanent addresses by deciding count by home visits, thus making the homeless "invisible." Nomenclatures and classification schemes are other examples that illustrate the deeply political nature of information infrastructures. These schemes form crucial parts of information infrastructures as they are standards that allow comparison across multiple contexts, but constructing these categories is a socio-politically and culturally shaped endeavour. Below we offer another example from the HISP activities, based on a study performed by a Mozambican doctor.

\subsection{The Constructed Nature of Representations}

The 2004 UNDP report states that HIV/AIDS prevails in $12.2 \%$ of the population between 15 to 49 years of age in Mozambique. This number is of course a construct, an estimate, rather than an exact measurement. If we "look behind" these numbers, we see how it is shaped by particular interests associated with the intended use of the information (Chilundo, 2004). These interests shapes how counting is done and what gets counted. In Mozambique, data on HIV/AIDS are collected from four segments of the population:

- surveillance data from pregnant women

- monthly routine reports from health facilities, including number of patients with AIDS symptoms

- results from testing of blood donors

- results of individuals who seek voluntary testing in test centers

Information Technology for Development DOI: 10.1002/itdj 
Every second year a sample of pregnant women seeking antenatal care is tested for HIV. This sample is drawn from a few districts (20 out of 144 districts), called sentinel sites, covering around $14 \%$ of the districts in the country. During the surveys, blood samples are taken for routine tests included in the antenatal care and reused to also perform HIV testing. The woman's name is not registered and she will not be informed about the result of the HIV test. The results from the sentinel sites are extrapolated to the other districts, based on factors that suggest common characteristics in terms of population mobility, road access, health services, culture and tradition, education level, and economic situation. Based on these estimates, software prepared by the UNAIDS/WHO is used to extrapolating these findings (i.e., number of pregnant women with HIV) to adult HIV prevalence rates. Another software application is then used to estimate the numbers of infected persons, the likely number of new infections and deaths. Additional information from models of epidemic patterns and population estimates are inputs to this estimation. Consequently, a small sample of pregnant women (around 1.2\%) is used to predict the HIV status of the entire population.

Patients presenting AIDS symptoms in hospitals are another source of information (although not reliable for various reasons). Very often diagnosis is based on clinical suspicion rather than laboratory tests, mainly due to resource constraints. Some of the patients go to higher-level hospitals, with separate reporting systems, and these cases will then not figure in the reports from the peripheral facilities. The number of AIDS cases is also systemically reduced for a number of other reasons. Nonsevere patients are not usually admitted to health centers but treated as outpatients. Furthermore, AIDS often will be hidden by the associated opportunistic disease. There are also significant practical, social, and economic constraints of limited access to health care and a reliance on traditional medicine as a first resort. The overall consequence of such factors is that the number of AIDS cases that get reported through this route is far less than estimates from projections. While much could be done to improve the reporting systems as such, the aim with our description is to emphasize a slightly different issue. Representations are shaped by the interests associated with its use. Epidemiologists and public health managers with aims of disease prevention, have rather different needs than, for example, those who offer patient-centered palliative care or those who oversee and manage health facilities. Such interests and needs shape how counting is done and ultimately what gets counted.

Standards of various kinds, technologies, and their effects embody interests and agendas. Related to the previous points, the installed base and the very result of development efforts are enabling but not so in an indiscriminate manner. Certain kinds of information, approaches, and opportunities will be discouraged and locked out. Power and control will be institutionalized and reinstitutionalized through development. Understanding and acknowledging these effects are vital for sustainable development. For example, the ownership of data and standards are not a-political. Around these issues, political negotiations related to implementation must be encouraged. In particular, different impacts of decisions on different stakeholders must be acknowledged.

\section{MULTIPLICITY OF NETWORKS}

Visions of all-encompassing, universal infrastructures are widespread, and, in this section, we argue for a critical reexamination of taken-for-granted notions such as universality, uniformity, coherence, and nonredundancy. A key expression of this is the pressure towards tighter or even "seamless" integration, where strong suggestive visions portray the 
benefits of tightly integrating currently dispersed, semiautonomous systems and modules (Monteiro, 2003). Yet, the actual realization of these visions of tightly integrated, universal infrastructures remains to be seen. We want to question the very ambition of these visions: What if they are not just difficult to achieve but inherently unattainable?

Several studies from the field of science and technology highlight the essential multiplicity of networks and focus on how ordering efforts does not eliminate but relocate disorder; order for one in one place is simultaneously disorder for another in another place. As Berg and Timmermans (2000) point out:

[T] hese orders do not emerge out of (and thereby replace) a pre-existing disorder. Rather, with the production of an order, a corresponding disorder comes into being ... The order and its disorder, we argue, are engaged in a spiraling relationship-they need and embody each other (p. 6-37).

Due to the multiplicity and complexity of the underlying networks, the very ordering efforts in themselves may produce the disorder. John Law (2003) underscores the ultimately dysfunctional nature of the ambition of full integration:

So what's the argument here? The answer is: It's an argument about imperfection ... that there are always many imperfections. And to make perfection in one place (assuming such a thing was possible) would be to risk much greater imperfection in other locations ... The argument is that entropy is chronic ... Some parts of the system will dissolve. (p. 11)

From these studies, we may gain the insight that "control-oriented" strategies are often unworkable related to complex systems (either of practical or of political reasons). Attempts to intervene and change may produce unexpected consequences; attempts to impose order in a collection of information systems through integration of multiple networks or standardization may relocate or generate only new disorder (Hanseth, Jacucci, Grisot, \& Aanestad, 2006). Studies such as these expose the naivety of efforts of integrating the comprehensive and dynamically shifting configurations of information systems. Integration, as a means to overcome a deep and self-reproducing source of heterogeneity, is unattainable (in a strict sense) given such a perspective. This has obvious, yet largely uncharted, implications for management and control of information systems development processes through the complexities and risks involved. In the following section, we provide another example of such multiplicity and diversity of information systems from the health sector of Mozambique.

\subsection{A "Spaghetti" of Systems}

One illuminating example of the multiplicity of networks is the health care information systems in Mozambique. Mozambique's aid dependence is extremely high, and it remains the largest single recipient of foreign assistance in Africa (Chilundo, 2004). This has resulted in a strong presence of donor agencies supporting the weakly developed national structures for health planning and management. Existing in parallel with government structures, there are multiple reporting systems belonging to vertical, disease-specific programs such as malaria, tuberculosis, leprosy, and HIV/AIDS. There is a general agreement that these systems overlap, but actually attempting to integrate these systems is complex and politically charged. The information systems are different in non-arbitrary ways: in relation to their history, how they are shaped by the characteristics of the problems (disease) addressed, and how they are embedded into different institutional settings at local, national, and 
international levels (Chilundo \& Aanestad, 2005). The differences between reporting systems can be illustrated by the three major programs of malaria, tuberculosis, and HIV/AIDS. The prevalence, incidence, mortality, and morbidity of the diseases, and also the attitudes toward the disease and the way treatment is organized, shape these programs.

The tuberculosis program deals with few cases relative to other communicable diseases; the disease is not acute, the treatment program is long term, and reporting is performed only quarterly. The disease is also well-known and treatment strategies are well established. Moreover, the program has strong financial backing and is perceived as successful. It thus has a long-standing and strong institutional basis, which extends beyond the national borders. One of the major concerns in the treatment of tuberculosis is to avoid the emergence of drug resistant tuberculosis bacteria. Thus, treatment is provided under a rigid regime involving close monitoring of drug administration to avoid a black market, and a patientcentered information system allows the program personnel to closely monitor the treatment progress for each individual.

In contrast, the infrastructure dealing with the HIV/AIDS pandemic is not equally well established. Compared to tuberculosis, HIV is a recent disease and treatment is still out of reach for most of the population. The voluntary HIV testing centres do not register personal information beyond demographic data like age, sex, etc., primarily because of the social stigma attached to HIV. Just as there have not been any treatment opportunities, there also have not been established systems to collect and maintain person-based information in order to follow up patients. The lack of treatment also provides less incentive for testing, and the policy has been geared more towards prevention, such as information campaigns and condom distribution. The situation is somewhat similar with regard to malaria, which, in general, is coped with through traditional medicine or with first-line drugs available at the black market, often without accessing health facilities.

Differences are not just between the programs, but also between the actors involved. The Ministry of Health recognizes the problem of overlap and the extra burden registration of redundant information put on already overworked health workers and the ensuing suboptimal functioning of the reporting and monitoring systems. To the Ministry, the activity of monitoring the effect of interventions and hopefully demonstrating progress is significant, as requested by both the donors and the general public alike. The donors' main interest is to ensure that their financial support is being well utilized and has desirable impacts. In this respect, supporting programs that are disease-specific or limited in other ways are easier to control, while round-sum budget support may be intractable in terms of monitoring where the money goes. While concerns such as these may be a reason to sustain vertical programs, the donor community also shares the concerns about overlapping systems, and the major donors cooperate towards integration by, for example, pooling their financial support into the Common Fund. However, the WHO has met criticism that their projects are rarely synchronized with the emerging processes aimed at developing their health systems. The evaluation of the Roll Back Malaria initiative found that the initiative was not linked up to sector-wide approaches, nor was it linked to the World Bank's poverty reduction strategies or its program of debt relief for heavily indebted poor countries (Yamey, 2002).

Consequently, the integration of information systems should not be perceived as primarily a technical issue, but rather as a complex and politically charged activity where multiple institutional influences and different, possibly competing, rationalities need to be aligned. The multiple reporting systems, the actors, and their interests should serve as a poignant reminder of our message that seeking for just one order may be futile and even dysfunctional. Orders, rationalities, and logics are multiple. This multiplicity cannot be eliminated; it must 
be negotiated, lived with, and handled in sensible ways. While a certain degree of technical integration may be feasible, information infrastructures involve a deep and self-reproducing source of heterogeneity. The challenge of development is thus acceptance, negotiation, and alignment rather than integration and elimination. Heterogeneity cannot be eliminated, but must be encouraged, negotiated, lived with and drawn upon. There is of course a balance point; we do not claim that all kinds of heterogeneity are good and beneficial and should not (or could not) be reduced. We want to maintain that in reality in order to live the "mess," we should also acknowledge ad hoc coping strategies as appropriate rather than striving for "the perfect."

\section{IMPLICATIONS FOR SDI AS PUBLIC GOODS}

Through our empirical descriptions and discussion, we have illustrated the relevance and benefits of several concepts related to information infrastructures. This should prove as a useful perspective on SDI design and implementation as information infrastructure. From a practical perspective, developing SDI to increase efficiency, transparency, and equity in developing countries is a complex if not daunting project. Each of the concepts we have discussed illustrates information infrastructure aspects that significantly contribute to these challenges. Based on an ambition to emphasise the public good character of SDIs, the concepts we have discussed are all centered on challenges related to the basic openness and sharedness of information infrastructures.

Previous discussions about public goods have focused on the role of governments and the implications of their withdrawal from public responsibilities in favour of market mechanisms. Our discussion of information infrastructure as a public good points in a slightly different direction. Information infrastructures are not provided by one provider for certain purposes but are built as a joint activity, and provide infrastructure upon which a range of activities can take place. In this process, information systems are no longer under central control, but become parts of networks on a different scale, where government(s), other institutional actors, and market actors influence to a varying degree the involved components and the overall development. At the same time, one important motivation behind creating such infrastructure is to initiate and nurture growth; thus, turning independent initiatives into parts of larger networks is a general way to success. With this perspective, information infrastructures are intrinsically public —open to different users and usages_-but not public and open for everything. Information infrastructures come with specific but different costs for the various actors involved in their building. What appears as a public good might not be public in the same way for all—only parts of the society may have sufficient access. Summing up, the information infrastructure perspective helps us tease out several fundamental challenges that are involved when attempting to establish large-scale, distributed technologies such as SDIs. Our emphasis on the public goods character of information infrastructures contributes through giving a normative direction to this enterprise, suggesting some general design criteria that should be salient in such significant undertakings.

An approach to understanding the interests and politics involved in development, as well as their effects by discussing information infrastructures as public goods, can provide a basis for collective action and development towards equity. Merely bringing forth and understanding the complexity of information infrastructures and the distribution of costs and benefits may not necessarily make a difference in itself, and may very well be contested. However, we hope that illuminating and communicating these issues may provide important 
inputs for an environment where design and strategy decisions become more transparent. If this can then further provide the potential for a new platform for negotiations, as well as building an environment where decisions and strategies can be evaluated and socially sanctioned, we believe that public goods SDIs are possible to realize.

The application of an information infrastructure perspective supports our understanding of what challenges SDI design and implementation in developing countries will encounter. Our findings are neither directly applicable nor suggesting simplistic approaches, but we believe that bringing forth these issues as a public goods discussion should provide useful as warnings and cautions. SDI may very well emerge as exacerbating inequalities and not provide equal opportunities for all. We thus emphasise that technological designs and implementations are significant, and not indifferent, in shaping our societies.

\section{REFERENCES}

Andrew, B. (2001). Political machines: Governing a technological society. London: The Athlone Press.

Berg, M., \& Timmermans, S. (2000). Orders and their others: On the constitution of universalities in medical work. Configurations, 8(1), 31-61.

Bergquist, R. (2001). Vector-borne parasitic diseases: New trends in data collection and risk assessment. Acta Tropica, 79(1), 13-20.

Bowker, G., \& Star, S. (1999). Sorting things out: Classification and its consequences. Cambridge, MA: The MIT Press.

Braa, J., \& Hedberg, C. (2002). The struggle for district-based health information system in South Africa. The Information Society, 18(2), 113-128.

Braa, J., Monteiro, E., \& Sahay, S. (2004). Networks of action: Sustainable health information systems across developing countries. Management Information Systems Quarterly, 28(3), 337-362.

Chilundo, B. (2004). Integrating information systems of disease-specific health programs in low income countries: The case study of Mozambique. Ph.D. Thesis Number 234, Faculty of Medicine, University of Oslo, Norway. Retrieved October 30, 2006, from http://www.ifi. uio.no/forskning/grupper/is/Thesis/ChilundoDissertation.pdf

Chilundo, B., \& Aanestad, M. (2005). Negotiating multiple rationalities in the process of integrating the information systems of disease-specific health program. Electronic Journal of Information Systems in Developing Countries, 20(2), 1-28.

Ciborra, C. (2000). From alignment to loose coupling: From mednet to www.roche.com. In C. Ciborra (Ed.), From control to drift: The dynamics of corporate information infrastructures (pp. 193-212). Oxford: Oxford University Press.

Ciborra, C., Braa, K., Cordella, A., Dahlbom Bo, Failla, A., \& Hanseth, O., et al. (2000). From control to drift: The dynamics of corporate information infrastructures. Oxford: Oxford University Press.

Clarke, K., McLafferty, S., \& Tempalski, B. (1996). On epidemiology and geographic information systems: A review and discussion of future directions. Emerging Infectious Diseases, 2(2), 85-92.

Craglia, M., \& Masser, I. (2001, December). Access to geographic information: A European perspective. Paper presented at the ESF-NSF Workshop on Access to Geographic Information and Participatory Approaches Using Geographic Information. Spoleto, Italy.

Dadzie, Y., Neira, M., \& Hopkins, D. (2003). Final report of the conference on the eradicability of onchocerciasis. Filaria Journal, 2(2).

de Man, E. (2004). And if geospatial data infrastructures were fragmented and splintering? Proceedings of the Seventh GISDECO International Seminar: GIS capacity building \& infrastructure. Johore, Malaysia.

Desai, M. (2003). Public goods: A historical perspective. In I. Kaul, P. Conceicao, K. Le Goulven, \& R.U. Mendoza (Eds.), Providing global public goods: Managing globalisation (pp. 63-77). Oxford: Oxford University Press.

Etya'alé, D. (2002). Eliminating onchocerciasis as a public health problem: The beginning of the end. British Journal of Ophthalmology, 86, 844-846. 
Georgiadou, Y. (2003, November-December). Reflections on the Indian NSDI. Geospatial Today, $21-23$.

Georgiadou, Y., Puri, S., \& Sahay, S. (2005a). The rainbow metaphor: Spatial data infrastructure organization and implementation in India. International Studies of Management and Organization, 35(4), 48-70.

Georgiadou, Y., Puri, S. K., \& Sahay, S. (2005b, May). Reflecting on national spatial data infrastructure implementation in India: The need for socio-technical approaches. In A. O. Bada \& A. Okunoye (Eds.), Enhancing human resource development through ICT: Proceedings of the Eighth International Working Conference of IFIP WG 9.4,. Abuja, Nigeria-.

Georgiadou, Y., Puri, S. K., \& Sahay, S. (2005c). Towards a potential research agenda to guide the implementation of spatial data infrastructures-A case study from India. International Journal of Geographic Information Science, 19(10), 1113-1130.

Giff, G., \& Coleman, D. (2002). Spatial data infrastructure funding models: A necessity for the success of sdis in emerging countries. Proceedings of the XXII Congress of the Federation Internationale des Geometres. Washington, D.C.

Grindley, P. (1995). Standards, strategy, and policy: Cases and stories. New York: Oxford University Press.

Groot, R. (1997). Spatial data infrastructure (SDI) for sustainable land management. ITC Journal, 3-4 287-294.

Guy, S., Graham, S., \& Simon, M. (1997). Splintering networks: Cities and technical networks in 1990s Britain. Urban Studies, 34(2), 191-216.

Hanseth, O., \& Aanestad, M. (2003). Design as bootstrapping: On the evolution of ICT networks in health care. Methods of Information in Medicine, 42(4), 385-391.

Hanseth, O., Jacucci, E., Grisot, M., \& Aanestad, M. (2006). Reflexive standardization: Complexity and side-effects in standard-making. Management Information Systems Quarterly, 30, 563 581.

Hanseth, O., \& Lyytinen, K. (2004). Theorizing about the design of information infrastructures: Design kernel theories and principles. Sprouts: Working Papers on Information Environments, Systems and Organizations, 4(4), 207-241. Retrieved October 30, 2006, from http://sprouts.case.edu/2004/040412.pdf

Hanseth, O., \& Monteiro E. (1997). Understanding information infrastructures. Unpublished Manuscript. Retrieved October 30, 2006, from http://www.ifi.uio.no/ oleha/Publications/bok.pdf

Hanseth, O., Monteiro, E., \& Hatling, M. (1996). Developing information infrastructure: The tension between standardisation and flexibility. Science, Technology and Human Values, 11(4), 407-426.

Hougard, J., Alley, E., Yaméogo, L., Yankum, K., Dadzie, \& Boatin, B. (2001). Eliminating onchocerciasis after 14 years of vector control: A proved strategy. The Journal of Infectious Diseases, 184(4), 497-503.

Hughes, T. (1979). The electrification of America: The system builders. Technology and Culture, 20(1), 124-161.

Hughes, T.P. (1987). The evolution of large technological systems. In W. Bijker, T. Hughes, \& T. Pinch, The social construction of technological systems: New directions in the sociology and history of technology (pp. 50-82). Cambridge, Mass: The MIT Press.

Kaul, I., Conceicao, P., Le Goulven, K., \& Mendoza, R. (Eds.). (2003). Providing global public goods: Managing globalisation. Oxford: Oxford University Press.

Kaul, I., Grunberg, I., \& Stern, M. (Eds.). (1999). Global public goods: International cooperation in the 21st century. New York: Oxford University Press.

Kaul, I., \& Mendoza, R.U. (2003). Advancing the concept of public goods. In I. Kaul, P. Conceicao, K. Le Goulven, \& R.U. Mendoza (Eds.), Providing global public goods. Managing Globalization. New York: Oxford University Press.

Law, J. (2003). Ladbroke grove, or how to think about failing systems. Retrieved October 30, 2006, from http://www.lancs.ac.uk/fss/sociology/papers/law-ladbroke-grove-failing-systems.pdf

Lewis, J. (2005). Design and development of a GIS spatial application for primary healthcare sector: Case studies from India and Mozambique. Unpublished master's thesis, Department of Informatics, University of Oslo, Norway.

Monteiro, E. (1998). Scaling information infrastructures: The case of next-generation IP in the Internet. The Information Society, 14(3), 229-245. 
Monteiro, E. (2000). Actor-network theory and information infrastructure. In C. Ciborra (Ed.), From control to drift: The dynamics of corporate information infrastructures. Oxford: Oxford University Press.

Monteiro, E. (2003). Integrating health information systems. Methods of Information in Medicine, 42(4), 428-432.

Ndengu, M. (2001). Spatial information for sustainable urban development: Using technology for informed decision making. Proceedings of the International Conference on Spatial Information for Sustainable Development, Nairobi, Kenya.

Nielsen, P. (2006). A conceptual framework of information infrastructure building. Unpublished doctoral thesis. Faculty of Mathematics and Natural Sciences, University of Oslo, Norway.

Porter, T. (1995). Trust in numbers: The pursuit of objectivity in science and public life. Princeton, NJ: Princeton University Press.

Puri, S. (2003). The challenges of participation and knowledge in GIS implementation for land management: Case studies from India. Unpublished doctoral thesis. University of Oslo, Faculty of Mathematics and Natural Sciences, Norway.

Rajabifard, A. (2002). Diffusion of regional spatial data infrastructures: With particular reference to Asia and the Pacific. PhD thesis, Geomatics, University of Melbourne. Retrieved October 30, 2006, from http://eprints.infodiv.unimelb.edu.au/archive/00001033/01/Rajabifard_thesis.pdf

Sahay, S., \& Walsham, G. (1997). Social structure and managerial agency in India. Organizational Studies, 18(3), 415-444.

Sen, A. (2000). Development as freedom. New Dehli: Oxford University Press.

Star, S. (1999). The ethnography of infrastructure. American Behavioral Scientist, 43(3), 377-391.

Walsham, G., \& Sahay, S. 1999. GIS for district-level administration in India: Problems and opportunities. Management Information Systems Quarterly, 23(1), 39-66.

World Bank (1993). World development report: Investing in health (Report No. 12183). Washington: World Bank.

World Health Organization (1978). Health for all. Declaration of Alma-Ata presented at the International Conference on Primary Health Care. Alma Ata, USSR.

World Health Organization (1998). Guidelines for analysis of remo data using GIS (TDR/TDF/COMDT/98.3).

Yamey, G. (2002). WHO in 2002: Faltering steps towards partnerships. British Medical Journal, $325(7374), 1236-1240$.

Zacker, M. (1999). Global epidemiological surveillance: International cooperation to monitor infectious diseases. In I. Kaul, I. Grunberg, \& M. Stern (Eds.), Global public goods: International cooperation in the 21st century. New York: Oxford University Press.

Margunn Aanestad, Ph.D., is Associate Professor at the Department of Informatics, University of Oslo. She has worked within health care and telecommunications before her doctoral study of surgical telemedicine. Her research interests are broadly related to design and evolution of largescale information infrastructures.Dr. Aanestad can be reached at margunn@ifi.uio.no

Eric Monteiro, Ph.D., is Professor at the Department of Computer and Information Science at the Norwegian University of Science and Technology. His primary field of interest is systems development when considering the challenges from integration, change, and standardization. He is particularly interested in the interplay between 'technical' and non-technical design decisions, and the problems related to the design of information infrastructure.Dr. Monteiro can be reached at ericm@idi.ntnu.no

Petter Nielsen, Ph.D., is a Research Scientist at Telenor Research \& Innovation. His Ph.D. discussed strategies for designing services for mobile telecommunication devices, and was built on empirical work around the development and standardization of a content service platform. His work is in extending the existing conceptual framework of information infrastructures to also discuss the construction activities of humans as information infrastructure builders and the institutional context in which their activities occur.Dr. Nielsen can be reached at petter.nielsen@telenor.com 